\section{NATURE AND TREATMENT OF CUTANEOUS CANCER.*}

BY A. RAVOGLI, M.D.

CINCINNATI, oHIo.

The heteroplasy, viz., normal epithelial cells in the wrong place, infiltrating the connective tissues of the parenchyma of the derma, or of the glands constitutes the essence of the cutaneous cancer, or epithelioma. It belongs to the class of the malignant growths on account of the persistent ulceration, of the tendency to recur after removal, of the infection which it produces in the tissues of the adjacent parts of the skin, and on account of the reproduction in the lymph-glands communicating with the lymphatic vessels of the affected part. It is not my object to develop the doctrine of cancers, which could not be done in the limits of a brief address, but I will only dwell on the nature of the cutaneous cancers and on their treatment.

Thiersch, in his remarkable work, published in 1865, on the epithelial cancers of the skin, distinguished two varieties from a topographical standpoint, one superfi-

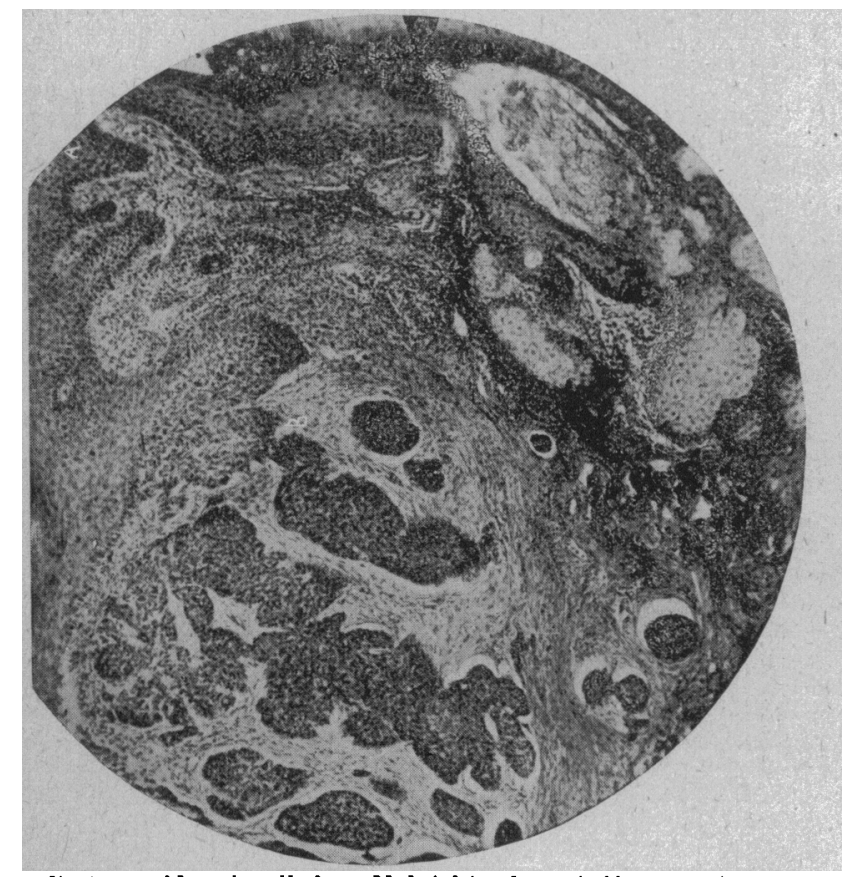

Fig.1-a,epidermic cells from Malpighian layer infiltrating the derma ; $b$, glands infiltrated with epithelial masses. Bausch \& Lomb, 1/4 obj.

cial, flache Hautkrebs, and another deep-seated, tiefgreifende Hautkrebs. These varieties of cancers are commonly accepted in the schools: 1, superficial, flat or discoid ; 2 , deep-seated or nodular; 3 , the papillary.

I have lately had under my observation many cases of the first kind. In one case it began in a gentleman, 40 years of age, who had always been healthy, in the form of small, minute, reddish nodules to the number of three or four, one close to the other, about the size of pinheads, forming a semicircle on the temporal region. He had a slight itching sensation, which made him scratch. Some of those nodules got ulcerated, and on this account he came to my clinic in the Ohio Medical College. The surface was repeatedly treated with different causties, but finding no result, we resorted to the excision of the diseased skin. The resulting wound was united with sutures, and in a few days healing was obtained. The affected skin was hardened in alcohol and

* Presented to the Section on Cutaneous Medicine and Surgery, at the Fifteth Annual Meeting of the American Medical Association, sections made for anatomo-pathologic study. (Fig. 1.) You can see the clearest picture of the superficial epithelioma. With a small power the epidermis shows that it is deprived of its horny layer and that very little of the stratum lucidum remains. The Malpighian layer is increased, and the epithelial cells enlarged and increased in size, containing large nuclei in masses; they are coming down between the papillæ, infiltrating the interpapillary spaces. The same hyperproduction of epithelial cells is found in the sebaceous glands, forming round nests between the stroma of the derma, round or irregularly shaped, filled up with a large quantity of the ephthelial cells. The derma is affected only in its superficial portion. With a stronger magnifying power you see that infiltration to be made up of roundish pearls, consisting of an enormous mass of large epithelial cells, nucleated, disposed in a circular way, and surrounded by connective-tissue fibers, which form the base of the pearl. The connective-tissue fibers do not show much change, with the exception of the invasion of the epithelial cells in their midst. It is clear that from the rete mucosum the epithelial cells make their way down between the papillæ. In this specimen you can see that

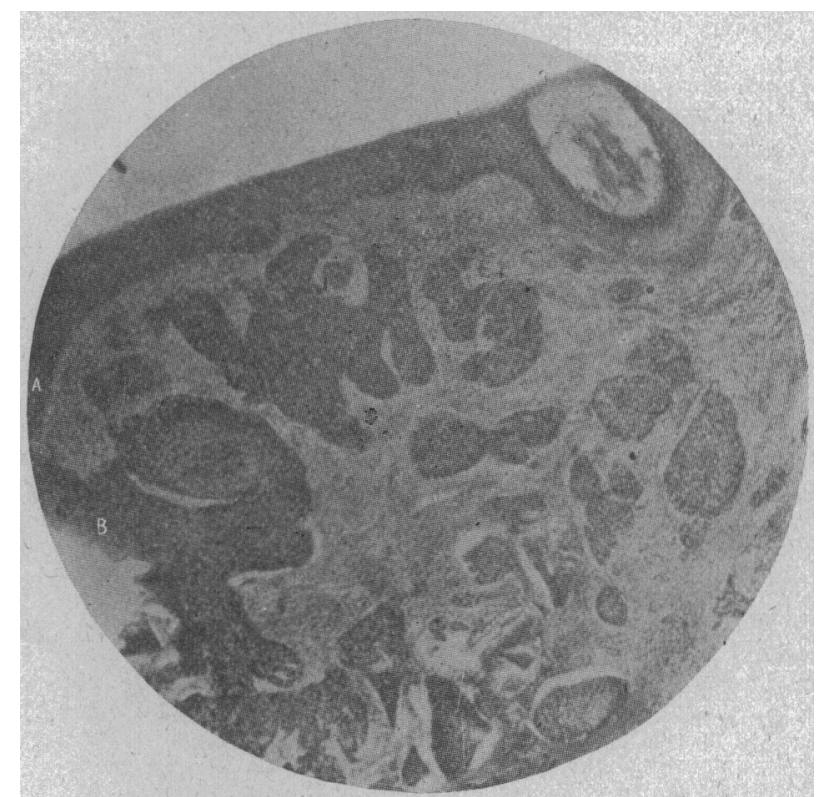

Fig.2-a, epitbelial cells from the Malpighian layer infiltrating papillary layer; $b$, masses of epithelial cells infiltrating the follicles of the skin. Bausch \& Lomb, $1 / 4 \mathrm{obj}$.

the blood-vessels are not much enlarged, and their tunics do not show decided alteration in their structure and in their condition.

In a lady 59 years old I had occasion to observe the same kind of superficial discoid epithelioma, lasting for over thirteen years, which had begun, as the patient says, from a small mole, which she used to pick with her finger-nails. She came to consult me some five weeks ago. The affection consisted of a red ulcerated patch, round in shape, with hard infiltrated edges, reaching the size of a silver dollar, on the right cheek and on the right side of the nose. On the cheek there is already a deep canceriform ulcer, with granulations bleeding easily, and discharging a thin purulent matter, concealed in the natural depressions of this region. It has been already treated with caustics and with salves of different kinds, but no result has ever been obtained.

The lady allowed me to scrape one of the granulations in the ulcer of the nose, which after having been hardened in alcohol was made in sections. (Fig. 2.) It was 
an interesting specimen of cancer of the glands. The epithelial infiltration was all around in the superficial derma. Its origin was from the Malpighian layer and from the glands of the skin. The epithelial cells were coming down in the interpapillary spaces, and the glands showed the infiltration of the epithelial cells in their parenchyma. In some points already some of the infiltrating cells had undergone some degree of degeneration. The blood-vessels were free from epithelial infiltration in their tunics, and it seems the whole infiltration of epithelial cells has its origin from the mucous layer of the epidermis and from the epithelium of the glands. Like in the other case, the epithelial cells are contained in nests in the interior of the glands, and no free infiltrating cells are found in the connective-tissue fibers of the superficial or of the deep derma, like we see in other species of cancer, where the infiltration seems to start from the bloodvessels.

The resulting ulceration of this kind of epithelioma is sometimes so superficial as to involve only the papillary layer of the derma. It heals in the center and spreads by its periphery. In some cases while healing

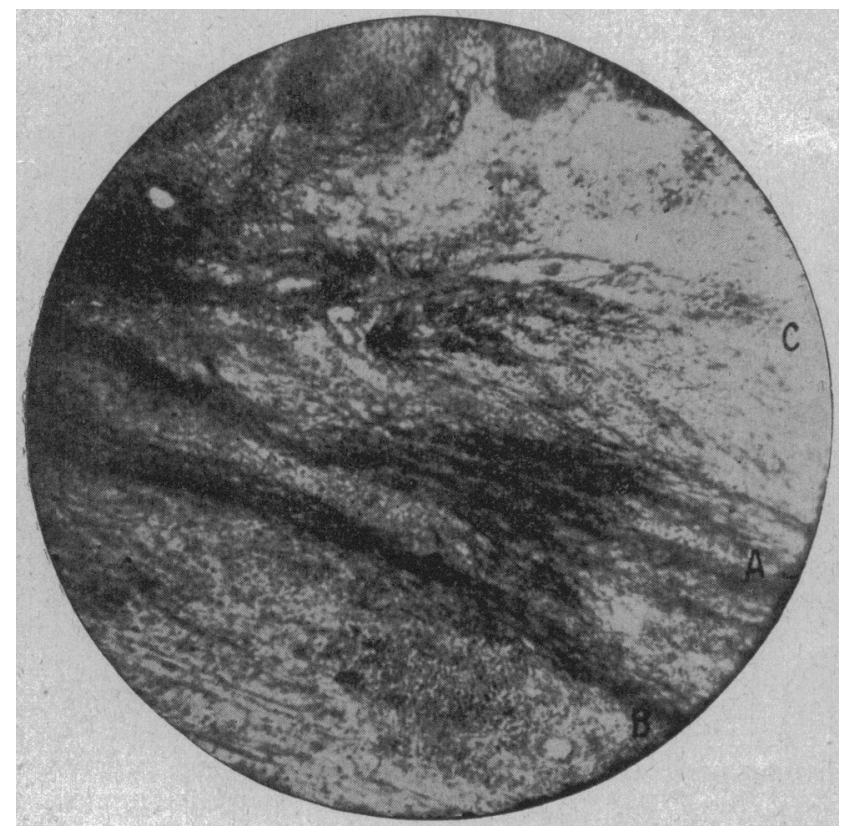

Fig. 3.-Deep carcinoma of the skin, $\alpha$, elastic fibers dividing the derma; $b$, epithelial cells infiltrating the connective tissues of the derma ; c, upper portion of the derma and papillary layer showing little infil. tration. Bausch \& Lomb, $1 / 4$ obj.

up in different parts it forms a deep ulcer around the periphery. This we find in the case of the gentleman represented in the illustration, as a case of epithelioma or uclus rodens of the temporal region. This patient has been affected with the present ulcer for the past eleven years. His photograph shows that a superficial alceration, with destructive results, has gone for a long time, judging from the scar remaining. In the last four years the ulcer showed a tendency to grow deeper and has caused a loss of substance in crateriform appearance. The bottom of the ulcer is covered with abundant round rose-red, large and succulent granulations, with the edges hard'ened and thickened. In some places the ulcer has gone so deeply as to show scales of necrotised bone. It is round in shape, touching the eyelids and covering an area between the temporal, zygomatic and frontal regions, about the size of a goose-egg. The granulations which cover the bottom bleed at any slight touch, and show deep impressions. They have, however, no tendency. to capillary excrescence like we see in other cancers. The edges, hard and infiltrated, show the fresh ulcerations from the breaking down of the new epitheliomatous nodules. One small piece of the skin near the edge of the ulcer was taken off and hardened in alcohol and then cut in sections.

In these specimens we find nearly the same appearances that we have found in those of the other cancers. The infiltration of the epithelial cells is greatly exaggerated. The immense quantity of cells is produced by the stratum spinosum of the epidermis which is directly connected with the masses of infiltrating cells among the papillæ. In this case we find that the inflammatory process is more advanced. There are many round inflammatory cells infiltrating the connective tissue. The connective-tissue fibers are already hypertrophied. Foci of degenerated cells can be seen in the midst of the infiltrating cells. The papillæ are enlarged, displaced and disfigured under the mass of the epithelial cells, which are crowding them up and filling all the spaces. In the lower layers of the derma, the infiltration seems due more to the inflammatory cells than to the infiltration of the epithelial cells. The fusiform cells are increased and swollen, and we can see a kind of new growth in the

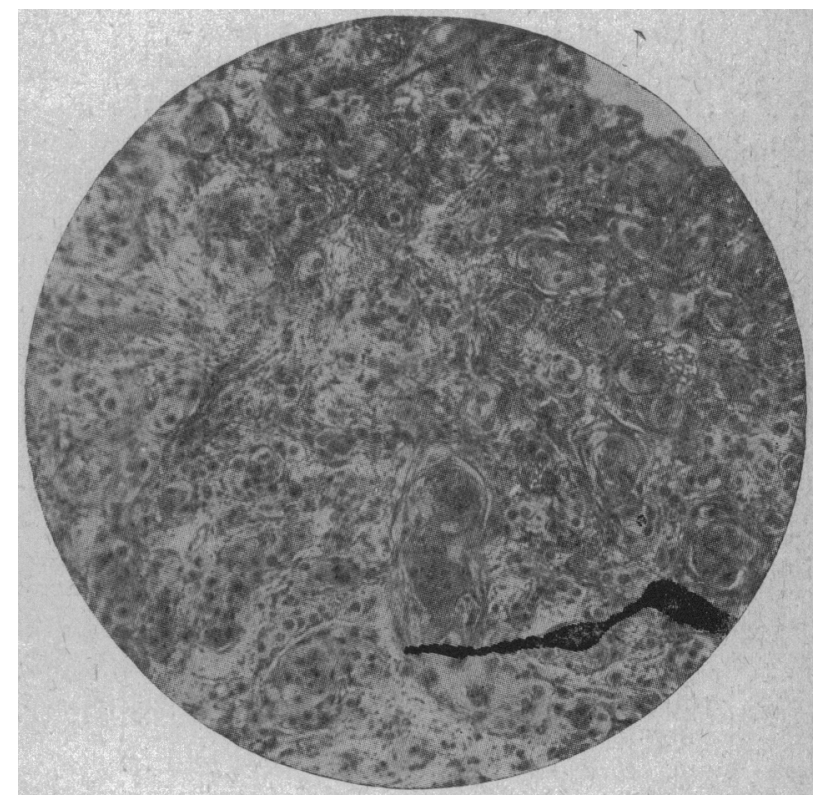

Fig. 4.-Epithelial cells infiltrating the connective tissues of the derma. $1 / 8$ obj.

fibrillary tissue. The growth of the connective tissue, however, does not reach the degree of hypertrophy which we find in the deep-seated cancerous forms, but on account of its resistance it never exceeds the level of the ulcer. The long-standing ulcer, without much discharge, is a characteristic of this disease. The granulations are covered by epithelium, but they are deprived of the horny layer. The stratum spinosum with the laver of epithelial cells is well developed, as you can see from the illustration, and the epithelial masses from it enter in the connective tissue forming the stroma of the derma. Sometimes in some points the ulcer is covered with epithelial masses simulating a kind of whitish superficial cicatricial tissue. From this covering of epithelial masses and from the resistance of the connective tissues can be explained the absence of pain, which is remarkable in these rodent ulcers. This cancer, however, like any other, can take the same appearance of the deep-seated. It loses that peculiar consistency and becomes softer; the collagenous substance and the fusiform cells dis- 
appear, nests of plasma cells remaining. The lymphatic spaces become enlarged, and the connective tissue takes a succulent appearance, becomes edematous, the nests of the epithelial cells have a tendency to liquefy, and the whole mass takes the form of a common carcinoma.

The second variety of skin cancer is that called deep-seated or nodular epithelioma. In some cases the affection may be the result of the first variety, or it begins directly as such. A kind of deep movable papule imbedded in the tissues of the skin is felt at the firststarting. It gradually grows to a tumor the size of a nut, hard, firm, elastic to the touch, with indurated prolongations in the subcutaneous tissue. The skin is elevated, glossy, pinkish in color, and covered with dilated capillaries. After a certain time ulceration takes place, sometimes on the surface; at other times breaking down in its center, destroying the epidermis and causing a deep undermined ulcer, surrounded by numerous other waxy nodules of the same nature.

In this variety of skin cancer the course is more rapid than in the first variety, and in a few years the lymphglands are involved and death takes place through marasmic condition. Several unfortunate cases of this kind have been lately under my observation. I will limit myself to two cases, which I consider were types of this carcinoma.

H. O., married, was admitted to the Cincinnati Hospital, Aug. 31, 1898, for a papillary growth on the glans penis and swelling of the inguinal glands of both sides. The growth was in the form of a cauliflower and occupied nearly the whole glans. The patient had first noticed a small wart, scarcely eight months before. I recognized the malignant nature of the growth and of the affection of the inguinal glands. On September 5 the penis was amputated and the glands of both groins perfectly extirpated. The patient recovered very promptly from the operation, the wounds were healing satisfactorily, but a secondary cancerous nodule appeared on the external region of the left hip. The patient was advised to have the growth removed, but he left the hospital Dec. 6,1898 . On Jan. 4, 1899, he was again admitted to the hospital. He was very much emaciated and weak. On the penis and on the scars of the inguinal region, where the glands had been removed, no signs of recurrent carcinoma could be found. A large growth about five inches in diameter and one inch above the level of the skin had its seat on the outer portion of the left hip. It was broken down, showing large and crateriform deep ulceration in the middle, discharging a thin serum of very offensive odor. On January 6 , Dr. J. C. Oliver operated on the patient. The whole tumor was removed, and four days later, after the necessary preparation, the whole surface was grafted with skin taken from the thigh. On February 6 everything seemed to be in a very satisfactory condition, but cancerous nodules began to appear all around the skin grafting, which in a few days attained the size of an English walnut. The grafting of the skin had taken very successfully; numberless cancerous nodules had developed.

The patient received injections of formalin, 1 to 5 per cent. in the cancerous nodules, of which we will speak later when treating of the therapeutic means for cutaneous cancer. Death occurred on April 2, from marasmus, the patient remaining for nearly one day unconscious. The post-mortem did not reveal any important vlceration in the different organs. The most important fact is that no secondary growths were found except in the skin and subcutaneous tissue, in the immediate locality of the penis, the inguinal region and the left thigh.
During life one nodule of the cancerous growth was excised, hardenea in alcohol, and sections made for anatomo-pathologic study. The epidermis had very little of its horny layer and scarcely a trace of stratum lucidum, but the stratum mucosum and spinosum is well maintained; the papillæ do not show much alteration, in fact the superficial layer of the derma has very little infiltration of epithelial cells and the infiltrating cells are more inflammatory cells. However, some bloodvessels can be seen greatly enlarged, and around them we find small nests of epithelial cells surrounded by fusiform cells from the connective tissues.

Fig. 3 gives an idea of this queer kind of carcinoma and gives a peculiar feature of the elastic fibers which, in longitudinal bunches, divide the derma into two layers; the superficial, which we have just studied, and the deep, which is enormously infiltrated with large epithelial cells in a reticular way. The epithelial cells are large, following the direction of the connective tissues, containing from two to six nuclei bound and connected together as in Fig. 4. In this specimen with a small power can be seen a kind of small alveolar structure, which is more apparent with a higher power, as in Fig. 5 , where the alveolar structure is clearer, each alveoli containing those large nucleated epithelial cells crowded together one upon the other. It corresponds to the description of the form called by Unna small alveolar cancer, where the alveoli contain no more than three or four epithelial cells of the glandular quality, and the alveoli in their disposition resemble somewhat the cerebral circumvolutions. In this case the connective tissue is reduced to less than its normal condition; mast cells and plasma cells are scarce ir number. The blood-vessels are enlarged, and the epithelium of the intima shows a great proliferation. (Fig 6, $1 / 8$ power.)

The vegetating form of epithelioma is nothing else than a variety of the deep-seated epithelioma, malignant and infectious. It is usually found in connection with other forms of carcinoma springing up from the cancerous ulcer, especially coming from mucous membranes. Its ordinary seat is the lips and the glans penis. The papillary growths project over the borders of the ulcer in the form of a cauliflower protrusion, very vascular, bleeding readily, spontaneously or in consequence of a slight touch. The lymphatic vessels become readily involved and the lymphatic glands show carcinomatous reproductions. They are capable, in three or four years, of causing death.

I will refer to a case of this kind which $I$ had in ${ }^{m}$ service in Cincinnati Hospital, and in which the patient died only a few weeks ago.

Wm. R., 39, years of age, born in Cincinnati from healthy parents, came to the hospital to be treated for an enormous papillary growth of the penis, scrotum and surrounding skin. Patient claimed that when 9 years old he fell from a ladder and caught the penis on an iron bolt and tore it. Some twelve years ago he contracted syphilis. Over three years ago the present affection began, in the form of a small hard pimple on the glans penis, above the meatus, not at all in connection with the scar of the already mentioned injury. Numerous warty productions appeared around the first until after six months from the appearance of the first nodule, he could not bring the foreskin over the glans. The production soon affected the whole skin of the penis and scrotum, often produced loss of blood, causing a remarkable emaciation.

It was a cauliflower growth involving the skin of 
the whole penis, which was adherent to the cancerous production of the scrotum, forming a round mass covered by large vegetations. The meatus was buried in the growth. The abdominal wall on one side and part of the perineum on the other was comprehended in the cancerous infiltration. Over the pubis was a large carcinomatous ulcer of the size of a half dollar. The subcrural and the inguinal glands were involved. The vegetations caused an abundant discharge with an offensive odor. At the slightest touch they bled profusely. The patient was exceedingly emaciated.

There was no possibility for any operation, and all that could be done was to limit the treatment to external applications and internal administration of tonics. The application of a solution of formalin, 2 to 5 per cent., for a short time every day, caused the necrosis of the papillary growths, which under a continuous bath of a solution of campho-phenique, sloughed off in a short time, bringing the whole mass down to nearly the normal condition.

An abundant suppuration began, with high temperature, gastro-intestinal disturbance; the patient became delirious and died.

The post-mortem revealed the carcinomatous production limited to the skin and subcutaneous tissue of the affected regions and to the lymphatic glands of the groins and the subcrural region. No reproduction of carcinoma was found in the internal organs. Liver, spleen

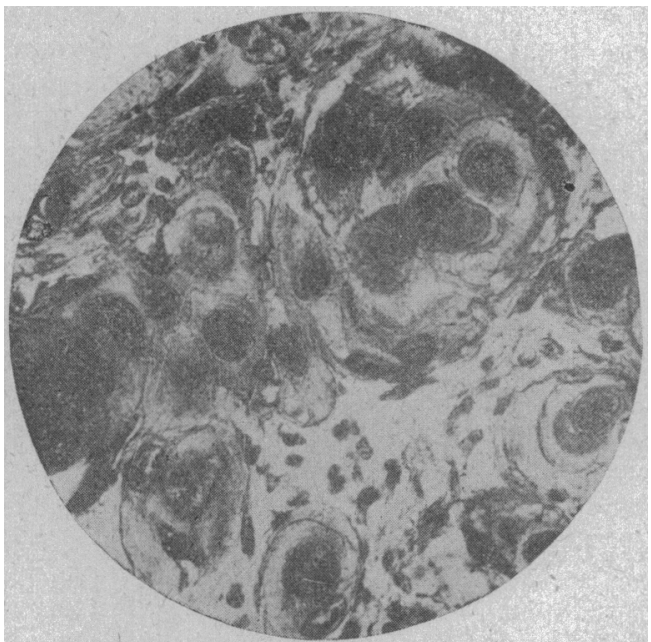

Fig. 5.-Large epithelial infiltrating cells surrounded by polynuclear connective tissue fibers. Immersion lens 1-12.

and kidneys showed that peculiar yellowish color and flaccidity which we find in cases of death from sepsis.

During life a piece of the affected skin of the penis was cut off, hardened in alcohol, and cut into sections for microscopic study. Fig. 7 with a small power shows the epidermis deprived of its horny layer, of which only shreds remain. The corpus mucosum hypertrophied, in a great mass, covers a quantity of elongated papillæ. Unna denies that the papillæ have anything to do with the old normal papilla of the derma. In nuy specimens it is clear that these papillæ have nothing to do with the normal papillæ, and you can see very clearly from the layers of the superficial derma spring up three and more papillæ with branches like trees, showing one to be the stem, from which others are coming up at different degrees of development. The papillæ are made up with connective-tissue fibers and the connective-tissue corpuscles are enlarged, but no epithelial cells could be found in their midst, so that they are simple connective-tissue growths without cancerous stroma. In the larger papillæ blood-vessels are seen in longitudinal arrangement, running into the papillæ. The epithelium is enormously increased on the top and in the interpapillary spaces; the epithelial cells largely increased in size are crowded greatly out of proportion. The cells which form the basal stratum are irregularly disposed. They do not maintain their cylindrical appearance, but are epithelial masses of different shapes. The connective tissue of the derma is greatly hypertrophied and many leucocytes are found infiltrating its meshes, showing a great relation to the lymphatic spaces. The bloodvessels are perceptible in great numbers, much enlarged and surrounded by infiltration of epithelial cells, and we can say that around the blood-vessels we find the true areolar stroma of the cancer. The cancerous infiltration is not so abundant, but its malignancy is superior to any other kind of cancer on account of the prompt affection of the lymphatics and of the lymphatic glands. I think that the luxurious growth of the papillæ is only the result of the hypertrophy of the connective tissue, through the irritation and the abundance of the vascularity, which causes the hypernutrition of these tissues. The papillary growth is not at all characteristic of the carcinoma, and really the reproductions of the carcinoma from a papillary one are of the nodular variety. For this

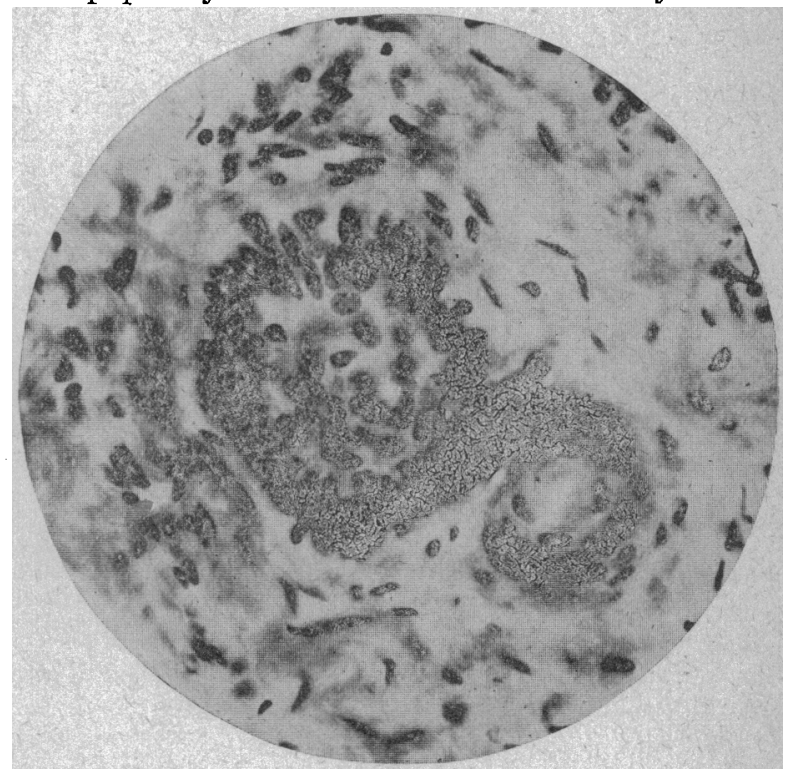

Fig. 6.-Epithelial cells, proliferation arising from the intima of the hlood-vessels. 1/8 obj.

reason $I$ believe it is not exactly necessary to consider the papillary cancer as a separate family of these tumors, but only a variety of the nodular or deep-seated leaving intact the fundamental classification of the cutaneous cancers, in superficial and deep-seated.

From the few anatomo-pathologic notes which I have given above I think that the most natural distinction of the epithelial carcinoma is the superficial, beginning its development in the superficial layers of the papillary layer, and second the deep-seated, nodular in the dermatologic sense, developing in the deep layers of the corium and affecting the surface only secondarily. I find that my ideas on this subject are in accordance with those expressed by Ernest Besnier and Dayon in the notes to the third edition of Kaposi. Unna ${ }^{1}$ very wisely objects to the mentioned distinction of the cutaneous cancers, believing it to be not only unnecessary butalso dangerous, on account of the confusion of the different forms already brought about. He claims that some authors have considered forms of cancer of a destructive nature, like

1 Die Histopathologie der Hautkrankheiten, Berlin, 1894. 
ulcera rodentia, as superficial and benignant. Indeed, the spreading of the cancer in the surface of the skin, the ulceration, the degeneration of the epithelial cells, are not enough reasons to authorize us to make the distinetion in flat and deep-seated. Any cancer malignant in nature, tending to metastasis, producing cachexia, is deeply seated, and yet every cancer has had an innocent local period, in which it was more or less superficial or flat.

I find, however, that the distinction of the cutaneous eancers in superficial and deep corresponds much better with the clinical observations and with the pathologic alterations. We have seen that in all the superficial cancers the derma is affected only in the most superficial layer, that the epithelial cells come down from the stratum spinosum of the epidermis and like indentations force their way between the papillæ, while in the second class of cancer we find the superficial layer of the derma little or not at all affected. T'he epidermis has no active part in the production of the epithelial cells infiltrating the tissues, but they are found in large quantities in loculi formed by the connective-tissue fibers in the deep layers of the corium. I find in my specimens that the production of these epithelial cells is greatly connected with the blood-ressels, as the intima shows a great proliferation, and the infiltration of these cells is more lbundant around the blood-vessels.

In my opinion the distinction of the epithelial cancers in superficial and deep-seated clinically gives us a clew for the prognosis and also for the treatment.

The sebaceous glands and also the sweat-glands are affected in their epithelium, and the glands are sometimes changed in a carcinomatous mass. Case 2 shows clearly the stroma of the gland disappeared and changed into a mass of epithelial proliferation. But I think that it would be rather difficult to base a distinction of the cancer on the different organs of the skin affected, and would not be of any benefit for clinical purposes.

The papillary cancer or cancer vegetans, which is so malignant, which so soon brings lymphatic cancerous reproductions, which in a short time causes cachexia, has to be considered only as a variety of the deep-seated cutaneous cancer. The papillary hypertrophy, the epithelial vegetations, are more secondary lesions than primary. In my photographs of the papillary cancer you have seen an enormous growth of the papillæ and hypertrophy of the connective tissues, but the epithelial infiltration you find mostly in the deeper layers of the corium and around the blood-vessels.

For these reasons I believe that this simple primary distinction of the cutaneous cancers is useful for the clinician, and all the other varieties based on the histology of the cancerous productions, on the form of the epithelial cells and on their disposition, are only of a secondary interest. In my specimen of the superficial cancer you will see that in every one there is the alveolar disposition of the connective tissues. The epithelial cells are completely surrounded and contained in loculi formed by the connective-tissue fibers. This peculiar feature is the reason that this kind of cancer can remain for many years, spreading very little, and producing no infection in the lymphatic glands. This is the reason why this kind of cancer has been said to be of a benignant nature, non-infecting; but the moment comes when it will show its malignancy like any other malignant growth of the kind. I have no intention of making of this kind of cancer, which has been called alveolar cancer, a principal variety. Histologically it will be interesting to distinguish the variety, but clinically it remains with the flat epithelioma, with its apparent benignancy and with its intrinsic malignancy. in the cells of the carcinoma there is a peculiar morbidity. They change places easily, as has been already observed by Waldeyer, and the cells around the nests show all the different shapes. This condition makes very easy the spreading of these cells through the lymphatic spaces and the lymphatic vessels. In Case 4 the secondary carcinomatous nodules followed exactly the path of the lymphatic vessels. The most common degeneration which the epithelial cells undergo in the alveola is the hyaline degeneration, although very rarely the keratodes and the calcifying degeneration may be found.

In my specimens I find a great difference in the formation of the carcinoma. In the superficial they show the epithelial cells coming down directly from the stratum spinosum, affecting primarily the papillary layer, and very little carcinomatous infiltration being found in the deep layers of the corium. In these cases the infiltration of the deep corium, especially in the ulcus rodens, was due to inflammatory cells. In cases of superficial cancer we find that the blood-vessels are normal and the epithelial cells are contained in alveoli formed by the connective-tissue fibers. The hypertrophy of the connective tissue was not so apparent as it was in the second variety. In the deep-seated cancer we have seen the palpillæ nearly normal and the epidermis without any apparent alteration. The infiltration of the epithelial cells is found mostly in the deepest layers of the corium. The blood-vessels are enlarged and a large quantity of epithelial cells are coming out of the intima of those vessels. The infiltration of the epithelial cells is found mostly around the blood-vessels, and for this reason I would not deny the possibility that the origin of the epithelial cells infiltrating the connective tissue can be found in the proliferation of the epithelium of the intima of the blood-vessels. In this deep-seated carcinoma we find that the infiltrating cells are not contained in loculi and restrained from spreading, but they infiltrate the connective tissues nearly free. With high power, however, we find that these large epithelial cells, furnished with enormous proliferating power, are also surrounded by some mast cells, and a few plasma cells, which constitute their nests.

From the histories of the patients and from the peculiar structure of the two classes of cancer, we can infer that although both diseases are of a malignant nature, yet the first is less infectious than the second, which in a short time reproduces on the lymphatic paths numerous carcinomatous nodules of the surrounding skin, soon causes cachexia, and leads the patient to a fatal end.

It is very hard to discuss the nature of cancer. Lebert and Hanover believed they had found the cancerous eell proper of these tumors, but this cancerous cell was nothing else than the epithelial cell in proliferation, which could not be differentiated from a physiologic cell. This apparent benignancy in remaining limited, at least for some time, caused the epithelial cancers to be considered as different forms, and for this reason Lebert called it psuedo cancer, and Hannover, epithelioma. From the works of Virchow, however, the malignant tumors were separated into the two classes, carcinoma and sarcoma. All tumors showing an alveolar structure with epithelial contents, were classed among the carcinoma, and from this time the epithelial cancers remained as true cancers.

The production of these epithelial masses was the great point to be established, and we find that Virchow 
and Foerster considered the epithelial cells as the production of the proliferation of the corpuscles of the connective tissues, independent of the pre-existing epithelium of the corpus mucosum and of the glands. Thiersh, on the contrary, establishes the origin of the cancer from the preformed epithelium, in consequence the pathologic production of the epithelial cells must be the result of the pre-existing epithelium. Thiersh, however, had neglected the alveolar structure, on which Rokitansky had previously insisted so much, and limited himself to the epithelial infiltration. Billroth found the epithelial infiltration in the connective tissue in consequence of the cancerous stroma necessary for the cancerous nature.

With all the studies of histology and of bacteriology, we are at the same point. We do not know what is the real cause of carcinoma. The theory of the parasitic elements already proposed claimed some protozoa to be the cause of the cancer. I only mentioned the studies of Darrier and Wickham on the Paget disease and the demonstration of the psorosperma and of the coccidia. I must say that for several years I have been a supporter of the psorosperma, but in these last years I was com-

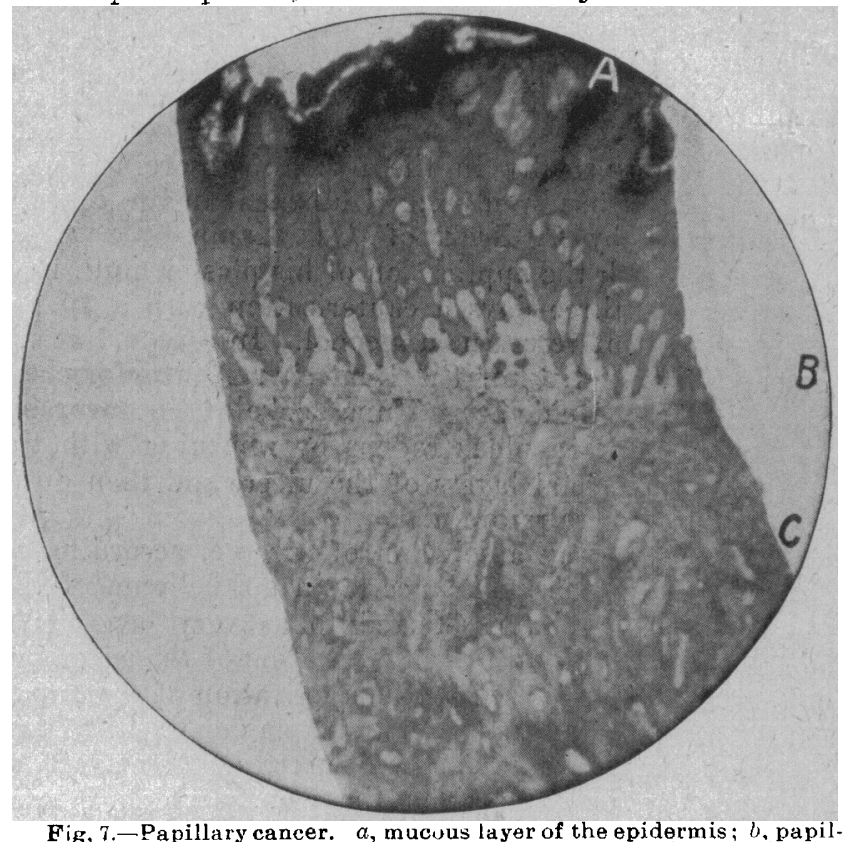

Fig. 7.-Papillary cancer. $a$, mucuus layer of the epidermis; $b$, papil le elongated and incre $t$ sed; $r$, derme infiltrated with epithelial cells and inflammatory elements. $1 / 1 \mathrm{obj}$.

pelled to modify my views and return to the same point. I do not know.

It is a very easy thing to prepare these large round bodies, which have been considered as coccidia, but when the same forms have been found in many other diseases of entirely different nature, it is our duty to disbelieve entirely this opinion.

What these round bodies are is explained by Unna ${ }^{2}$ and Boeck ${ }^{3}$. They are of the opinion that these bodies are produced by epithelium in hyaline degeneration. The apparent peculiarity and specificity soon disappear, comparing these large round bodies with hyaline epithelium found in other dermatoses. We have seen in the previous histologic considerations, that in carcinoma very frequently the cpithelium is affected with hyaline degeneration. Unna explains the vitreous ring which is seen around the round corpuscle to be the result of a swollen hyaline ectoplasma, and the internal narrow with double contour as endoplasma, which in some

2 Die Histopathologie der Hautkrankheiten, Berlin. 1894, p. 286.

3 Vier Fälle vor Darier'scher Krankheit. A.A. 1891 . epithelium is only compressed, in others it is in hyaline degeneration. Two epithelial cells, one close to the other, hardened in hyaline degeneration, may form a ring with two Darrier's bodies, which is two nuclei covered by one endoplasma. And again when young epithelial cells are affected with hyaline degeneration, when the distinction in endoplasma and ectoplasma has not yet begun, the hyaline masses are formed with wellpreserved nuclei. and this is that which makes the Darrier's round corpuscles. The hyaline degeneration affects young and old cells of the stratum spinosum, and the finding of more nuclei in one cell is the result of several cells affected with hyaline degeneration in close connection. From these considerations the coccydium is

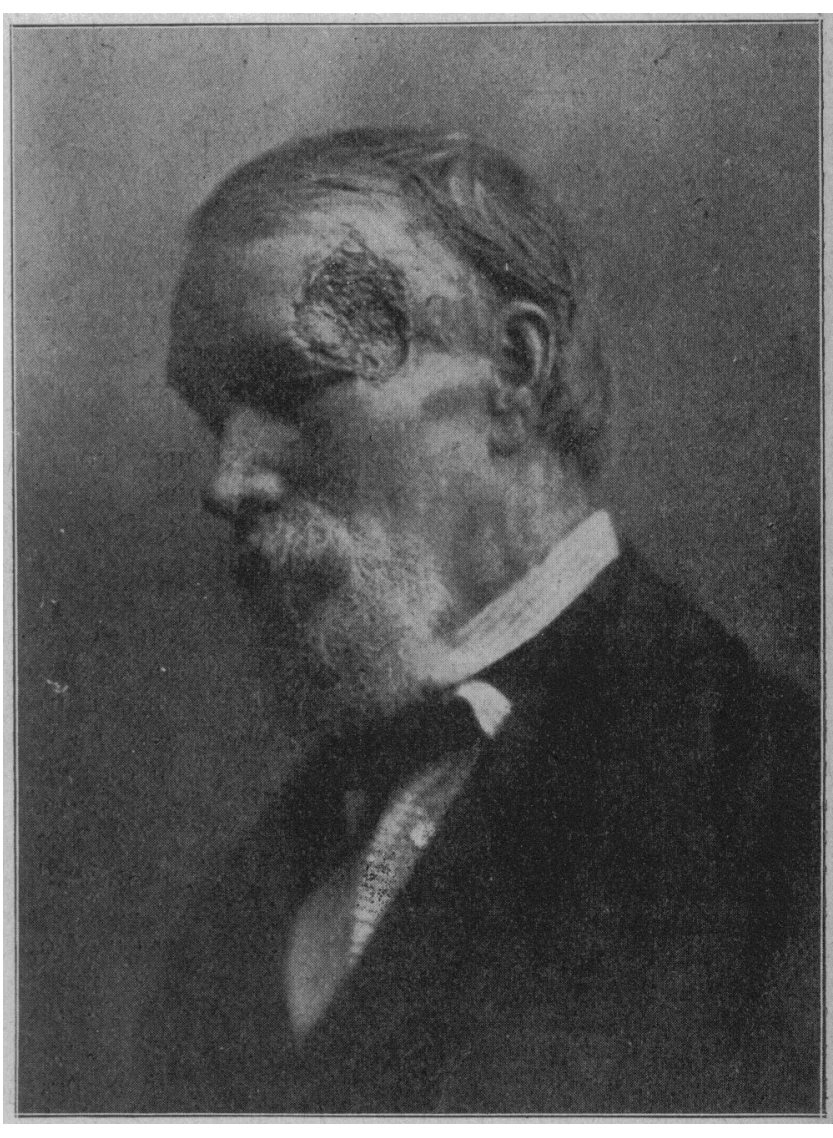

ULCUA RODENS.

nearly out of question, and there remains only the supposition of the parasitic origin of the carcinoma.

I will only mention that lately this subject has been approached from the side of the essential vitality of the epithelial cells and their reaction to various irritants ${ }^{4}$. Dr. Hektoen, in his review of this subject, in "Progressive Medicine," refers to the experiments of Dr. Ljunggren, who could preserve pieces of human skin in sterile ascitic fluid for months, the cells of the tissues retaining their vitality. Pieces of skin kept in such sterile fluid for a month were successfully transplanted, and it could be found that a proliferation of epithelial cells had occurred. In the same review Hektoen refers to some obscrvations made here in the United States by Loeb. He writes that from the margin of a tissue defect, huge epithelial protoplasmic or plasmodal masses, move in a sliding manner over the marked surface, inclosing and dissolving the crust and their obstacles. Regenerating epithelium readily removes such substances as cartilages when placed in its way. Below

\footnotetext{
4 The Virginia Medical Semi-Monthly, March 24. 1899.
} 
the protoplasmic layer, epithelial cells wander in from the margins of the defect and often grow down into the connective tissue, apparently checking the growth of the latter. This process is closely allied to the changes which occur in carcinoma. Locb believes that the wandering of the cells is in response to stereotropism, and forms a determining factor in inducing mitosis in the remaining cells. The action of the epithelial elements to arouse at a distance the germinal activity of the epithelial cells constitutes the essence of the carcinoma.

These physiopathologic studies are in relation to clinical observation. Indeed, we must say that cancer is developed in parts which have been exposed to a continuous irritation. The cancer of the lips and of the tongue in inveterate smokers shows that this epithelial proliferation in the tissues is preceded by a constant irritation. A patient lately came under my observation with an epithelial cancer in the form of a bracelet around the middle of his forearm, and he explained to me that the disease was due to his habit of carrying every day for many years a heavy market basket on that arm. Every patient tells us that he had a small wart or mole, which he was in the habit of picking with his finger-nails, and in consequence caused the ulcer. I believe that a continuous irritation to any part of the skin is the starting point of the epithelial proliferation and of the consequent epithelial cancer.

Epithelioma has been often seen on lupus; from the lupus ulcers start epitheliomatous conditions. Cases of this kind have been referred to by Bidault, Raymond, Hutchinson, Kaposi, etc. The question is whether the cancer is developed in the cicatrix or in the lupus ulceration. Hutchinson ${ }^{5}$ gives a fine illustration of lupus cancer in a woman who had suffered from lupus for about thirty years, and on the scar of lupus on her upper lip a malignant growth had taken place. It seems that the scars are often the starting point of the cutaneous cancer, as the pars minoris resistentiae. It is singular that the course of the epithelioma in the scars is slower than in the normal skin, and usually the ulcerative forms are more frequent than the papillary.

I cannot neglect one of the most interesting questions : whether syphilis has any influence on the production of the cutaneous cancer. There are some syphilitic ulcerations which easily can be mistaken for epithelioma. In case of a slight doubt of the existence of syphilis, before operating on an epithelioma the patient must first be subjected to an antisyphilitic treatment. I do not believe in any mixture of syphilis and cancer, but for the reasons already expressed, cancer can develop on a syphilitic ulcerative process or on a scar of a syphilitic ulceration. In this regard Besnier refers to a paper of $\mathrm{F}$. H. Ozenne: "Du cancer cher. les Syphilitiques, de l'hybridité cancero-syphilitique de la cavite buccale en particulier." These de Paris, 1884.

The author believes in the association of cancer and syphilis, forming a mixed condition, a well-defined pathologic hybridity. The antisyphilitic treatment may improve this condition for a short time, but later the cancer continues its destructive course. In a few cases which I have had under observation, I have found it rather difficult to establish the exact diagnosis from the clinical symptoms, and only the anatomo-pathologic study can furnish us the differential diagnosis. Syphilis is the cause of irritation, creates partes minoris resistentiae, which can be later affected by cancer. It seems that syphilis diminishes the virulency of cancer, but gradually disappears from the scene, and the cancer con-

5 Smaller Atlas of Illustrations of Clinical Surgery, London, 1895. tinues in its destructive activity. In conclusion, both diseases have nothing in common, only syphilis may cause cancerous productions on account of its long-standing ulcerative process.

Treatment. - It would require a long article to review all the different remedies, caustics, and methods of treatment for the cutaneous cancer. I must state that the distinction of these affections into superficial and deep-seated is a great help in the choice of the method of treatment to be adopted for the different cases. The base of treatment is to destroy the growth as soon as possible, and to destroy it deeply and at a certain radius of distance, to be sure to have removed the tissues where a potentiality of development of the infiltrating cells can be found. The methods of destroying the cancer can be reduced to cauterization, curettement and surgical exeresis.

Cauterization can be done with any kind of caustic which destroys the tissues, or with the actual cautery. A large number of substances have been employed to destroy superficial cancers, with different results. Local applications of acetic acid have been recommended by Arnozan ${ }^{6}$. The application of the Vienna paste, the mixture of Manec, arsenious acid 2, sulphate of hydrarg. 6 , calcinated sponge 1.2 , and the application of chlorid of zinc, have been praised as a chemical means of destroying carcinoma.

Resorcin, especially in the form of resorcin plaster mull of Unna ${ }^{7}$ has been used with benefit in two cases of ulcus rodens by $\mathrm{C}$. Beck of Christiania. Unna, in association with the application of his plaster mull, used every two or three days a cauterization with a 10 per cent. solution of resorcin in alcohol. In a report at the sixty-second meeting of the Deutscher Nauturforschers und Aertze, in Heideiberg, Unna spoke of the favorable results obtained in ulcus rodens by removing with the knife the superficial layers of the ulcer, and then dusting over with pure resorcin.

In the same way a solution of arsenic, according to the method of Czerny-Trunecek, in epithelioma of the inferior lip, has been referred to as very beneficial ${ }^{8}$. 'This method consists in the scarification of the epitheliomatous surface, followed by the application of a solution of arsenic acid, $1 \mathrm{gm}$., alcohol and aqua destil. aa. $75 \mathrm{gm}$. I can say that I have used a great many of these caustics, but none so far have given the results which I have lately obtained from formalin.

A lady, Mrs. B. McD., came to me for a recurrent superficial carcinoma of the left cheek, the size of a 25-cent piece, touching the inferior eyelid and the nose. It had been already scraped and cauterized by a colleague, but the ulcer returning, the lady called on me. I proposed the removal of the growth, to which the lady objected. I began to use several different remedies, among them caustic potash and resorcin, but after the necrotic portion had sloughed off the growth was progressing in its course. I was just using a 4 per cent. formalin solution to harden some microscopic sections made through the freezing microtome, and seeing the wonderful action upon the tissues, I thought I would try it on the carcinomatous. The ulcer was covered with cotton saturated with a solution of formalin, and kept on for nearly thirty minutes. The lady complained of a sharp pain, and soon a mild dermatitis followed which in two or three days subsided. When the patient came back, all the carcinomatous nodules were changed

6 Bulletin de la Soc. Franc. de Derm. et de Syph., 1890.

7 Monatsheft f. Pract. Dermatologie, Band vii, No. 4, p. 173.

8 Presse Medicale. 1898, No. 75. 
into a white yellowish mass adherent to the tissues, and this gradually sloughed off leaving good tissue underneath. From 4 per cent. I reached 8 per cent. and 10 per cent. solutions, and finally I began to apply the pure solution as it comes in commerce prepared by Merck, under the name of formaldehyde. In a few weeks the ulcer was healed up and I was able to show her to the Academy of Medicine of Cincinnati on account of the remarkable result;.

Encouraged by this success I began to treat Mr. P. B., 68 years of age, an engineer, for an ulcus rodens of the left portion of the nose, from the tip to its base. For over seventeen years he had been affected with this disease. With repeated applications of formaldehyde-at times an 8 per cent. solution, at times just as it comes in commerce- $\mathrm{I}$ have succeeded in obtaining recovery of the whole ulcerated surface. At present there remains a small nodule inside of the nostril, which was cauterized with the remedy mentioned. In the second case referred to I am using formalin to touch up the surface of the cancerous growth, and the improvement is very remarkable. In a patient in the hospital, a lady 52 years of age, with a small superficial carcinoma of two years' standing, I have cauterized the growth with a paste made out of starch, prepared chalk and oxid of zinc, equal parts, incorporated with formaldehyde to make a paste. This paste has been applied twice, and at present the whole growth is changed into a black hard crust, which is gradually detaching from the normal tissue. Before applying the paste we cocainize the surface so as to diminish the pain, and it is also necessary to corer the eyes with cotton so as to prevent the vapor of the formaldehyde from irritating the conjunctivæ. In a case of nodular cancer reported, formaledehyde, from 1 to 5 per cent., was injected with the Pravatz syringe in the carcinomatous nodules. The injection caused the breaking down of the nodules and an abundant sloughing, but it was stopped on account of the resulting pain. In the papillomatous carcinoma of the penis already referred to, the applications of a solution of formaldehyde, from 4 to 8 per cent., for half an hour every day, caused necrosis of all the papillary growths, so that in a few weeks the cnormous mass was reduced to nearly the normal size.

Formaldehyde ${ }^{8}$ has powerful bactericidal properties, as was pointed out by Locu, 1886, and later by Aronson, Berlioz and Trillat. When formaldehyde gas in solution was added to cultures of bacteria, Pattevin found that their growth was arrested. It is obtained by the action of methyl alcohol vapor and air on platinum heated to redness. The process was difficult and dangerous on account of its explosiveness, but lately it has been modified and rendered very simple. Formaldehyde is not poisonous in the strict sense of the word. In some ex. periments on animals during disinfection maintained for several hours, no one of the animals died. It is considered the most powerful non-toxic antiseptic and bactericide. Introduced into the circulation it is poisonous, on account of the coagulation of the blood, which it easily induces: and if introduced into the stomach, it causes a violent irritation with vomiting. In many patients while using formaldehyde freely on the affected surface, it has never caused any general trouble of the nervous system.

It seems that the penetrating power of formaldehyde is greater than is usually supposed. Professor De Rechter of Brussels was testing its power on human and animal cadavers exposed to the fumes of 40 per cent.

\footnotetext{
${ }^{9}$ Formaldehyde. Its Nature, Properties and Uses. By F. E. Stewart, M.D. Merck's Archiv., January, 1899.
}

formaldehyde. 'The cadavers could be kept for months withoui any trace of decomposition, or if it had already begun it was immediately checked by the vapor of the formaldehyde. In cadavers of guinea-pigs that had died from anthrax or tuberculosis, and also in the lungs from tuberculous cows, the organs were found completely sterile in two to six days. The tests prove that the formaldehyde penetrates the whole substance of the cadavers and kills the bacteria and anthrax spores in them.

From these considerations on the physiologic action of formaldehyde, there is reason to believe that from its penctrating power it is able to reach the nest of cells of the superficial cancer and reduce them to a hard detritus, which is subsequently sloughed off from the normal tissues. In order to increase its action, when applying the paste it is better to cover the paste with a piece of rubber or of oiled silk, so as to prevent its rapid evaporatior.

I consider formaldehyde in superficial cutaneous cancer as one of the best local applications we have. It is non-poisonous, therefore there is no danger as in the application of arsenic paste; it has the power of penetration into the tissues, therefore an action which spreads deep into the tissues, destroying the cancerous infiltrations. The deep-seated nodular carcinoma of the skin has also been treated by bathing with a 4 to 6 per cent. formaldehyde solution, and I must say that in spite of the bad condition of the locality, the patient has been benefited by these applications.

The curettement, used a great deal by Kaposi and also by Bessnier, is a good method for a superficial epithelioma, if followed by cauterization, even with the thermocautery, or with formaldehyde. The curettement removes the cancerous tissue on the surface, but does not remove the whole affected mass. Many nests of cells remain in the surrounding derma which the curette can not reach; in consequence, relapse is promptly at hand. But when the curettement is followed by a thorough cauterization, then it is one of the best therapeutic means we have.

When we have to do with a deep-seated, nodular carcinoma, or with the papillary vegetating cancer, the surgical exeresis is the best treatment. The removal of the whole growth at some distance from the healthy skin is the only means of destroying the growth and preventing infeciion. In the cases where the lymphatic glands near by are involved, it is necessary to resort to surgical extirpation of the Jymphatic glands in order to prevent relapse.

In the unfortunate cases where the growth has taken such proportions as in our two cases above referred to, any surgical operation is absolute!y impossible, and we must remain powerless spectators of the destruction.

The method of Coley, of injections with the solution of cultures of bacillus prodigiosus and streptococcus erysipelatis has been tried, but the results have been entirely negative. I have used this method in a few cases. but the results have been such as not to invite me to further experiments. The same ideas I find expressed by B. Korff in his paper, "Uber Carcinombehandlung mit Streptococcus prodigiosus Kulturen, und negativem Resultat."11

At this point the patient is already greatly emaciated, the cachexia is rapidly increasing, the extensive ulcers are discharging offensive matter, yet a solution of 2 per cent. of formaldehyde left for some time on the

10 Munich Med. Woch., October 4.
11 Wien. Med. Wocl.., 1897, No. 12. 
ulcers in the form of compresses, cleanses them, removes the offensive odor and diminishes the seropurulent discharge. In this case formaldehyde is only a simple auxiliary means, which comes handy in those hopeless cases.

\section{RECENT PHASES IN PSYCHIATRY.*}

BY WILLLAMT G. STEARNS, M.D.

Lecturer on Mental Diseases and Medical Jurisprudence, Northwestern University Medical School; Late Superintendent Illinois Eastern Hospital for the Insane (Kankakee). CHICASO.

When I first began the study of insanity I thoroughly and comparatively read several standard works on mental diseases, and after finishing them I had no clear comprehension of one single psychosis. It was only after much clinical study, in which no reference was made to text-books, that I gained any satisfactorily definite knowledge of mental diseases.

The confusion arising to the student from the many different bases for classification, and the consequently large number of terms for the different abnormal mental states is most bewildering. It has been said of the alienist that, when he thinks he has finished his studies, he constructs a classification. While $I$ have not finished my studies, l, nevertheless, have been unable to find in a. text-book a classification that for my own clinical use formed a practical working basis. I am not alone in this attitude, and yet when working side by side with men who chafed as badly as I under the yoke of this or that classification, we could not agree among ourselves as to a proper one. The classifications of no two authors agree in all important points. Different authors name over fifty different manias and as many melancholias. There must be something radically wrong about a science that finds its followers so far apart.

With the methods in use, clinical study of the insane offered but very slight inducement to the ambitious student. Observations as to the frequency and effect of intercurrent or concomitant discases, consideration of the causal factors and experimentation with therapeusis seemed to give the only chance for the gaining of tangible results. Even these fields had been trodden almost bare by the alienists of the present century. There seemed to be no way, no means by which we could scientifically investigate abnormal mental phenomena, and thereby gain a clear comprehension of mental diseases. The methods in rogue enabled us to speculate, to philosophize, to theorize-to what end? Only to make a new classification representing one's individual ideas of mental pathology with which he could not hope that any other fellow observer would fully concur. The fault lay not with the observer, kut with his methods of research.

For nearly two years, with a well-equipped microscopic laboratory and two assistants, I devoted almost my entire time to the study of the pathology of the insane, making in all over four hundred post-mortem examinations. Many interesting cases were thoroughly examined, and from the standpoint of the neurologist much that was important was brought to light, but comparatively little data was acguired that would help one to a better understanding of the true nature of mental disease. Nevertheless, we have a right to expect much from histopathology, but a marked improvement in laboratory technique will be necessary before any material advance can be made, and histopathology can never give an adequate foundation for the study of abnormal

\footnotetext{
*Read before the Chicago Academy of Medicine, May, 1899.
}

mental phenomena. It may, and undoubtedly will, help to explain clinical data, and confirm theories suggested by clinical observation by demonstrating the physical basis, for it will explain the end, but can not become a means to that end. The brain does not, gland-like, secrete thought. Thought being neither a secretion nor material, can not be examined by the methods of histopathology.

No professor would think for one moment of teaching diseases of the digestive organs to a class who did not have a fair understanding of the physiology of digestion. How many courses in mental diseases are given to-day, in medical colleges of the best repute, in which there is absolutely no reference made to the physiology of the mind? But a few days ago, on carefully looking over my synopsis of the course in mental disease which I give in the Northwestern University Medical School, a prominent neurologist and an experienced teacher made the single suggestion that he thought that I spent too much time in the rudiments. In the course, the first five lessons were devoted to the physiology of the mind, under the caption of "Mental Organization."

In considering the most prevalent methods of the study of insanity, we can not fail to notice that psychiatry shows, more clearly than any other branch of medical science, the effect of philosophic theorizing and the dearth of scientific research. Alone, the purely mental phenomena of insanity give a foundation for but little that is not speculative. Attempts to build up the science on such groundwork have brought to psychiatry a wealth of conflicting views that have bred a bewildering profusion of terms and classifications that still, to a certain extent, act as a barrier to helpful co-operation among alienists.

Of all sciences, the psychology of but two decades past was perhaps the most imperfect. Notwithstanding its having long been popularly classed with the natural sciences, if we understand a science to be related knowledge obtained by special research and accepted by the consensus of reliable specialists, psychology has not until recently merited the name of science. This want of consensus is most apparent. Even in fundamental points the manuals of psychology do not agree, while in the manuals of physics, geology or botany there is practical unanimity.

Psychology has until recently been little more than introspective speculation, often senseless and ridiculous. The elaborate webs of philosophy woven by the old school psychologists could, therefore, give no practical working basis to the alienist. However, as natural philosophy paved the way for and was gradually supplanted by natural science, so the philosophic abstraction of the psychology of a few years ago is fast giving place to the experimental scientific psychology of to-day. Since the founding of the first psychologic laboratory in Leipzig, in 1878, problems have been solved which the philosophic school regarded as unanswerable. The conflicting philosophies, as well as the traditions of the alienists, are now giving place to facts established by scientific investigation. Psychology as an experimental science refuses to depend on foregone metaphysical conclusions, and bases its investigations on demonstrable facts.

The reflex act is recognized as the fundamental element in all action, voluntary or involuntary, from the simplest motion to the most complicated performance. Every motion, every activity of animal life, from the simplest movements of the amebæ to the most compli- 